Economics Development Analysis Journal 7 (2)(2018)

\title{
Strategi Peningkatan Pengelolaan Persampahan di Kecamatan Ngaliyan Kota Semarang
}

\section{Ivan Septiawan ${ }^{\bowtie}$}

Jurusan Ekonomi Pembangunan, Fakultas Ekonomi, Universitas Negeri Semarang

\begin{tabular}{l}
\hline Info Artikel \\
\hline Sejarah Artikel: \\
Diterima Januari 2018 \\
Disetujui Maret 2018 \\
Dipublikasikan Mei 2018 \\
\hline Keywords: \\
Strategy, Management, \\
hygiene, Analysis Hierarchy \\
Process
\end{tabular}

\begin{abstract}
Abstrak
Produksi sampah setiap hari semakin meningkat seiring dengan bertambahnya jumlah produk dan pola konsumsi masyarakat. Masih belum optimalnya dalam pengelolaan sampah dikarenakan kurangnya pelayanan penanganan sampah, kurangnya kejelasan kelompok sasaran/masyarakat dalam menerima informasi. Dalam penelitian ini terdiri dari 10 keyperson yang terdiri dari unsur akademisi/peneliti, pemerintah, dan masyarakat. Adapun metode penelitian yang digunakan adalah analisis deskriptif dengan teknik analisis AHP. Dari penelitian diperoleh hasil olah data menggunakan analisis hirarki proses (AHP) dapat terlihat bahwa strategi peningkatan pengelolaan persampahan/ kebersihan di Kecamatan Ngaliyan Kota Semarang tersusun atas beberapa kriteria program yang di prioritaskan dalam pembentukannya yaitu pertama kriteria peningkatan penanganan pelayanan sampah (nilai bobot 0,504), kedua kriteria pengembangan sistem pembiayaan (nilai bobot 0,268 ), dan ketiga kriteria aspek peran masyarakat (nilai bobot 0,228 ). Adapun saran dari penelitian ini antara lain diharapkan pemerintah dan pihak yang berkepenting berkenan untuk mengaplikasikan kebijakan berdasarkan hasil penlitian ini.
\end{abstract}

\begin{abstract}
Still not optimal in waste management is due to the lack of services handling junk, the lack of clarity of the target groups / communities in receiving the information, the less communication apparatus implementing higiene, low levels of public participation. The sample in this study consists of 10 keyperson consisting of academics/researchers, Government, and society. As for the research method used is descriptive qualitative analysis with AHP analysis techniques. The results obtained from the study of sports data using the analysis hierarchy process $(A H P)$ can be seen that the increase in the levy of service persampahan strategies/hygiene in the Subdistrict Ngaliyan Semarang city composed of several criteria the programs in priority in the formation of the first criterion, namely the improvement of the handling of waste services (value weighted 0,504), these two criteria development financing system (value weighted 0,268), and the third aspect of the role of Community criteria (the value weights 0,228). As for the suggestion of this research, among others, expected the Government and interested parties deign to apply policies based on the results of these studies. As well as by the existence of socialization and information service of persampahan retribution which must be further enhanced and focused service junk handler.
\end{abstract}

(C) 2018 Universitas Negeri Semarang 


\section{PENDAHULUAN}

Kota pada umumnya merupakan pusat sebagian besar kegiatan perekonomian, perdagangan, industri, pemerintahan maupun pendidikan. Semakin bertambahnya aktivitas manusia di perkotaan membawa dampak meningkatnya tuntutan masyarakat kota akan pentingnya harapan hidup lebih tinggi, sejahtera, ketentraman, ketertiban dan kenyamanan (Sutarto, 2004:1).

Daerah kabupaten/kota diberi peluang dalam menggali potensi sumber-sumber keuangannya dengan menetapkan jenis retribusi selain yang telah ditetapkan, sepanjang memenuhi kriteria yang telah ditetapkan dan sesuai dengan aspirasi masyarakat.

Salah satu jenis retribusi yang cukup potensial yaitu retribusi pelayanan kebersihan / persampahan (Yani, 2002:63). Sedangkan menurut Hardiyansyah (2011:14) Banyaknya jenis pelayanan umum di negeri ini dengan macam-macam persoalan dan penyebab yang sangat bervariasi antara satu dengan yang lainnya, sehingga perlu dicari suatu metode yang mampu menjawab persoalaan pelayanan. Menurut Fitriana (2013:30)
Persampahan/Kebersihan merupakan instrumen kebijakan yang dilakukan oleh pemerintah dalam upaya untuk mengatur kesadaran masyarakat akan pentingnya kebersihan baik di lingkungan tempat tinggal maupun di lingkungan kota. Kebijakan retribusi sampah dalam konteks otonomi daerah diambil oleh Pemerintah Daerah di Indonesia untuk meningkatkan pendapatan asli daerah (PAD).

Manajemen merupakan suatu proses kegiatan mengelola sumber-sumber daya untuk mencapai tujuan seefisien mungkin (Suseno dan Sunarto, 2012). Lingkungan perkotaan yang baik, bersih dan rapi merupakan idaman bagi semua warga masyarakat.

Pesatnya pembangunan Kota Semarang diikuti dengan peningkatan jumlah penduduk yang berdampak pula pada volume sampah yang diproduksi. Dengan adanya peningkatan jumlah penduduk maka mengakibatkan produksi sampah meningkat selain itu juga menimbulkan dampak buruk bagi pemerintah jika tidak segera ditangani maka perlu adanya pengelolaan persmapahan/ kebersihan yang baik. Berikut data perkembangan penduduk Kota Semarang 2011-2015.

Tabel 1. Data Perkembangan Penduduk Kota Semarang

Tahun 2011-2015

\begin{tabular}{llll}
\hline Tahun & Luas Daerah $\boldsymbol{k m}^{\mathbf{2}}$ & Jumlah Penduduk & $\begin{array}{l}\text { Kepadatan } \\
\text { Penduduk } \\
\mathbf{k m}^{2}\end{array}$ \\
\hline 2011 & 373,67 & 1.555 .984 & 4.164 \\
2012 & 373,67 & 1.585 .417 & 4.243 \\
2013 & 373,67 & 1.629 .924 & 4.362 \\
2014 & 373,67 & 1.644 .800 & 4.402 \\
2015 & 373,67 & 1.672 .999 & 4.477 \\
\hline
\end{tabular}

Sumber : BPS Provinsi Jawa Tengah, 2011-2015

Berdasarkan tabel 1.1 jumlah penduduk di Kota Semarang tahun 2011 sampai tahun 2015 cenderung meningkat setiap tahunya sedangkan luas daerahnya tetap. Hal ini mengakibatkan
Kota Semarang menjadi pusat kota yang menyumbang sampah terbanyak. Berikut data sumber dan volume sampah di Kota Semarang 2015. 
Tabel 2. Sumber dan Volume Sampah di Kota Semarang 2015

\begin{tabular}{llll}
\hline No & Sumber & $\begin{array}{l}\text { Volume } \\
(\mathrm{m} 3 / \text { hari })\end{array}$ & Persentase (\%) \\
\hline 1 & Pemukiman & 3935.09 & 84,64 \\
2 & Hotel & 48,00 & 1,03 \\
3 & Pasar & 117,30 & 2,52 \\
4 & Pertokoan & 28,00 & 0,60 \\
5 & Rumah Sakit & 55,00 & 1,18 \\
6 & Perkantoran & 56,00 & 1,20 \\
7 & Fasilitas Umum & 76,00 & 1,63 \\
8 & Industri & 120,00 & 2,58 \\
9 & Jalan Protokol & 164,00 & 3,53 \\
10 & Rumah Makan & 50,00 & 1,07 \\
& & 4650 & 100 \\
\hline
\end{tabular}

Sumber : Dinas Kebersihan dan Pertamanan Kota Semarang, 2015

Seperti yang telah disebutkan di atas bahwa salah satu timbulan sampah yang paling banyak adalah sampah rumah tangga $84,64 \%$, kemudian sampah pasar $2,52 \%$ dan sampah kawasan industri 2,58\%. Besarnya produksi sampah di Kota Semarang tidak lepas dari semakin meningkatnya jumlah penduduk Kota Semarang. Setiap individu pasti menghasilkan zat sisa atau limbah atau sampah, sehingga semakin bertambahnya penduduk maka semakin bertambah pula sampah yang dihasilkan.

Menurut Slamet (1996:154) kualitas dan kuantitas sampah sangat dipengaruhi oleh berbagai aktivitas dan taraf hidup masyarakat. Beberapa faktor penting yaitu jumlah penduduk semakin banyak maka jumlah sampah yang dihasilkan semakin meningkat.

Kemudian Sosial Ekonomi, semakin tinggi kondisi sosial ekonomi masyarakat semakin banyak jumlah sampah yang di buang dan yang terakhir Kemajuan Teknologi, kemajuan teknologi akan menambah jumlah kualitas sampah karna pemakaian bahan baku yang semakin beragam, cara pengepakan dan produk manufaktur yang beranekaragam pula. Menurut rochman dalam jurnal suseno dan sunarto (2012, vol 5) manajemen lingkungan dapat diartikan sebagai ilmu dan seni untuk menggunakan sumber daya lingkungan secara efektif, efisien dan rasional untuk mebncapai kondisi lingkungan yang ditetapkan sebeumnya. Daerah pinggiran kota masih dianggap sebagai tempat paling mudah untuk membuang sampah. Apabila hal ini tidak ditangani dan dikelola dengan baik, peningkatan sampah yang terjadi tiap tahun itu bisa memperpendek umur TPA dan membawa dampak pada pencemaran lingkungan, baik air, tanah, maupun udara. Sistem pengumpulaan yang tidak tuntas, kurangnya alat angkut sampah, dan terbatasnya kapasitas tempat pembuangan akhir sampah (TPA) menjadi permasalahan yang khas mencakup aspek teknis, sosial, dan budaya. Penataan lingkungan yang tidak baik dan pengelolaan lingkungan hidup yang tidak teratur berakibat timbulnya berbagai masalah seperti banjir, tanah longsor, dan bencana alam lainya. Berikut data Volume sampah rata-rata perhari $\mathrm{Di}$ Kota Semarang Per/Kecamatan Tahun 2015.

Terlihat dari tabel 1.3 bahwa Kecamatan Ngaliyan merupakan salah satu Kecamatan sebagai penghasil produksi sampah terbesar di Kota Semarang. Kecamatan Ngaliyan memiliki jumlah populasi penduduk yang cukup tinggi Pengelolaan sampah yang dilakukan pada suatu daerah akan mempengaruhi kualitas lingkungan pada daerah tersebut meskipun dampaknya tidak terlihat secara langsung.

Yang menjadi indikasi masalah penelitian dalam pengelolaan sampah ini yaitu, masih banyak masyarakat khususnya di Kecamatan Ngaliyan yang tidak mengetahui tentang peraturan daerah retribusi persampahan sehingga pelaksanaannya tidak efektif, serta masyarakat merasa pelayanan yang dilakukan oleh pihak yang bertugas tidak memuaskan sehingga kemauan untuk membayar tidak ada. 
Tabel 3. Volume Sampah Rata-Rata Per Hari Di Kota Semarang Per/Kecamatan Tahun 2015

\begin{tabular}{lllll}
\hline Kecamatan & $\begin{array}{l}\text { Jumlah Produksi } \\
\text { Sampah (M3) }\end{array}$ & $\begin{array}{l}\text { Jumlah } \\
\text { Terangkut (M3) }\end{array}$ & $\begin{array}{l}\text { Sumpah } \\
\text { Tak } \\
(\mathrm{M} 3)\end{array}$ & $\begin{array}{r}\text { Sampah } \\
\text { Terangkut }\end{array}$ \\
\hline Mijen & 119,38 & 89,53 & 29,85 \\
Gunungpati & 180,94 & 135,7 & 45,24 \\
Banyumanik & 329,18 & 246,88 & 82,3 \\
Gajah Mungkur & 181,15 & 135,86 & 45,29 \\
Semarang Selatan & 245,63 & 184,22 & 61,41 \\
Candisari & 244,63 & 183,47 & 61,16 \\
Tembalang & 325,29 & 243,96 & 81,33 \\
Pedurungan & 433,7 & 325,27 & 108,43 \\
Genuk & 198,29 & 148,71 & 49,58 \\
Gayamsari & 198,75 & 149,06 & 49,69 \\
Semarang Timur & 257,53 & 193,14 & 64,39 \\
Semarang Utara & 386,33 & 289,74 & 96,59 \\
Semarang Tengah & 243,03 & 182,27 & 60,76 \\
Semarang Barat & 461,61 & 246,2 & 115,41 \\
Tugu & 76 & 57 & 19 \\
Ngaliyan & 327,57 & 245,67 & 81,9 \\
\hline
\end{tabular}

Sumber : BPS Kota Semarang Dalam Angka 2015

Dengan adanya masalah tersebut tentu membawa pengaruh terhadap peningkatan pengelolaan persampahan/kebersihan Kota Semarang. Oleh sebab itu, pemerintah perlu memikirkan hal ini secara serius serta berusaha melakukan upaya pengoptimalan peningkatan pengelolaan persampahan/kebersihan.

Menurut jurnal Haryanto (2011) dari penelitian terdahulu masalah penanganan sampah masih belum mendapat perhatian utama dari masyarakat. Masyarakat masih mengandalkan penanganan sampah dari petugas yang diberikan dari pemerintah, khususnya pengangkutan sampah. Maka dari itu penanganan sampah harus di ratakan ke seluruh permukiman di Kota Semarang.

Kemudian menurut Saputro (2015) sampah dapat dikelola dengan cara menerapkan bank sampah di setiap daerah. Tetapi dengan menerapkan bank sampah ini harus diperhatikannya pelayanan atau jasa pengelolaan sampah untuk masyarakat, agar masyarakat merespon.

\section{METODE PENELITIAN}

Data yang digunakan dalam penelitian ini adalah jenis data primer dan sekunder. Data primer dalam penelitian ini yaitu data yang dikumpulkan dan diolah sendiri oleh organisasi yang menerbitkan atau menggunakan. Data primer ini digunakan untuk mengambil kebijakan dalam analisis Hierarki Proses (AHP).

Menurut Jumna (2015) data primer untuk perumusan kebijakan dalam Analisis Hierarki Proses (AHP) diperoleh dari key-persons. Penentuan dalam pemilihan alternatif program apa saja yang dapat ditempuh untuk ditentukan dan yang harus diprioritaskan. Data sekunder yaitu data yang diperoleh dari instansi terkait, 
yiatu Badan Pusat Statistik (BPS) dan Dinas Kebersihan dan Pertamanan Kota Semarang.

Penelitian ini menggunakan Metode analisis Interaktif dan Analisis Hierarki Proses (AHP). Metode analisis interaktif dilakukan dengan mereduksi data sebagai proses pemilihan setelah itu melakukan dengan mengecek kembali hasil reduksi yang telah dilakukan yaitu dengan cara triangulasi. Dalam penelitian ini variasi teknik yang digunakan adalah triangulasi model sumber. Hal ini dilakukan menggunakan wawancara, dokumentasi dan observasi yang dilakukan terhadap masyarakat di Kecamatan Ngaliyan.

Kemudian Analisis Hierarki Proses (AHP) dengan tujuan untuk mengetahui program manakah yang perlu didahulukan atau diprioritaskan dalam upaya meningkatkan pengelolaan persampahan/kebersihan di Kecamatan Ngaliyan. Oleh karena itu penelitian ini membutuhkan beberapa pihak yang dianggap berkompeten (key-persons) yang mewakili untuk menetukan alternatif - alternatif program dalam upaya peningkatan pengelolaan persampahan/ kebersihan di Kecamatan Ngaliyan Kota Semarang.

Ada beberapa program-program dalam upaya meningkatkan pengelolaan persampahan/kebersihan di Kota Semarang yang ditawarkan oleh stakeholder terkait, yaitu:

Program 1: Penerapan dan peningkatan sistem pengelolaan persampahan/ kebersihan.

Program 2: Penerapan sarana dan prasarana pengangkutan sampah ke TPA dan penentuan lokasi TPA yang aman.

Program 3: Penerapan sistem pengumpulan sampah.

Program 4: Penetapan biaya tarif retribusi pengelolaan persampahan/ kebersihan sesuai golongan.

Program 5: Penetapan biaya tarif langsung dan tidak langsung ke TPA.

Program 6: Meberikan pelayanan pembayaran dengan cara online.

Program 7: Partisipasi masyarakat dalam meningkatkan pengelolaan persampahan/kebersihan.
Program 8: Memberikan kesadaran masyarakat untuk mengelola sampah guna peningkatan pengelolaan persampahan/kebersihan.

Program 9: Pelaksanaan informasi dan sosialisasi pengelolaan sampah yang sistematis.

Analisis Hierarki Proses (AHP) adalah suatu metode yang sering digunakan untuk menilai tindakan yang dikaitkan dengan perbandingan bobot kepentingan antara faktor serta perbandingan beberapa alternatif pilihan. Metode AHP merupakan suatu model yang diperkenalkan oleh Thomas L. Saaty pada tahun 1993.

\section{HASIL DAN PEMBAHASAN}

Strategi Peningkatan Pengelolaan Persampahan/Kebersihan Melalui Alat Analisis AHP, Retribusi persampahan/kebersihan di Kota Semarang saat ini diatur dengan menggunakan Peraturan Daerah Kota Semarang Nomor 2 Tahun 2012 tentang Retribusi Jasa Umum di Kota Semarang. Perda tersebut pada dasarnya mengatur pungutan yang dilakukan oleh Pemerintah Kota Semarang kepada masyarakat atas jasa penyelenggaraan pelayanan pengangkutan sampah dari TPS ke TPA dan yang membuang langsung di TPA. Dalam Perda tersebut, objek retribusi pelayanan persampahan/kebersihan di Kota Semarang adalah pelayanan persampahan / kebersihan yang diselenggarakan oleh Pemerintah Kota Semarang, khususnya:

Pengambilan dan pengangkutan sampah dari sumber sampah ke lokasi tempat pembuangan/pemusnahan/pemrosesan akhir sampah untuk sampah niaga. Pengambilan dan pengangkutan sampah dari tempat penampungan sementara ke lokasi tempat pembuangan/pemusnahan/pemrosesan akhir sampah untuk sampah bukan niaga.

Sedangkan subyek retribusi pelayanan persampahan/ kebersihan adalah orang pribadi atau badan yang mendapatkan jasa pelayanan persampahan/ kebersihan dari Pemerintah Kota Semarang. Retribusi persampahan/kebersihan adalah pungutan yang dilakukan oleh Pemerintah Kota Semarang kepada masyarakat 
atas jasa penyelenggaraan pelayanan pengangkutan sampah dari TPS ke TPA dan yang membuang langsung di TPA. Pelaksanaan retribusi pelayanan persampahan/kebersihan, pembayaran retribusi sampai saat ini dapat dilakukan pada:

Kantor Perusahaan Daerah Air Minum (PDAM) Tirta Moedal Kota Semarang, $\mathrm{RT} / \mathrm{RW} /$ Kelurahan bagi yang tidak berlangganan PDAM, UPTD TPA bagi yang membuang langsung di TPA, Dinas Kebersihan dan Pertamanan, memungut retribusi persampahan/ kebersihan niaga.

Sistem Teknik Operasional pengelolaan persampahan di Kecamatan Ngaliyan Sangat ditentukan volume sampah yang diangkut atau dibuang ke tempat pembuangan akhir. kegiatan operasional persampahan tergantung pada polapola operasional yang digunakan, cara penyapuan, pengumpulan, pangangkutan dan pembuangan akhir. Teknis operasional pengelolaan sampah di Kecamatan Ngaliyan terdapat 4 pola pengelolaan sampah yaitu:

Pembuangan langsung ke tempat terbuka atau tempat pembuangan sementara (TPS) yaitu, masyarakat yang melakukan pembuangan langsung ke pekarangan, tempat terbuka atau tempat pembuangan sementara.

Pelayanan sampah konvensional yaitu melakukan dengan pengangkutan sampah dari sumber sampah hingga kepembuangan akhir.
Pembuangan langsung ke TPA atau tempat pembuangan jatibarang yaitu Merupakan mode bagi kegiatan industri atau sarana prasarana lain yang membuang sampah dengan kendaraan operasional ke TPA.

Pengelolaan sampah yaitu merupakan mode pengelolaan sampah yang dilakukan dengan mengolah sampah menjadi produk daur ulang.

Dalam meningkatkan pengelolaan persampahan/kebersihan, pelayanan persampahan/kebersihan masih belum merata ke seluruh wilayah Kota Semarang khususnya di Kecamatan Ngaliyan sehingga pelayanan saat ini masih menjadi masalah dalam meningkatkan pengelolaan persampahan/kebersihan di Kecamatan Ngaliyan Kota Semarang.

Berdasarkan pendapat gabungan para keyperson menunjukan bahwa kriteria Peningkatan pelayanan penanganan sampah (nilai bobot 0,504) merupakan kriteria paling penting yang perlu diperhatikan dalam strategi peningkatan pengelolaan persampahan/kebersihan di Kecamatan Ngaliyan Kota Semarang. Kriteria berikutnya adalah pengembangan sistem pembiayaan $(0,268)$ kemudian kriteria Partisispasi masyarakat $(0,228)$.

Tabel 4. Kriteria Peningkatan pengelolaan Persampahan/Kebersihan

\begin{tabular}{lllll}
\hline NO & Program & & Nilai Bobot & Keterangan \\
\hline 1 & $\begin{array}{l}\text { Berbasis Peningkatan } \\
\text { Penanganan Sampah }\end{array}$ & Pelayanan & 0.504 & Inconsistency Ratio = \\
& $\begin{array}{l}\text { Berbasis Pengembangan } \\
2\end{array}$ & Sistem & 0.268 & \\
3 & $\begin{array}{l}\text { Pembiayaan } \\
\text { Berbasis Aspek Partisipasi Masyarakat }\end{array}$ & 0228 & \\
\hline
\end{tabular}

Sumber : Data Primer diolah, 2016

Hasil olah data AHP untuk menentukan aspek yang menjadi prioritas telah memberikan informasi mengenai aspek apa saja yang harus diperbaiki atau dikembangkan guna peningkatan pengelolaan persampahan/kebersihan di Kecamatan Ngaliyan Kota Semarang. Adapun hasil AHP ini diperoleh dari keyperson yang menjadi responden. Selanjutnya aspek-aspek yang menjadi kriteria dari yang prioritas hingga yang paling tidak ini akan diurai lagi kedalam alternatif-alternatif dari masing-masing prioritas tadi. 
Aspek terpenting menjadi prioritas dalam peningkatan pengelolaan persampahan/ kebersihan di Kecamatan Ngaliyan Kota Semarang adalah aspek peningkatan pelayanan penanganan sampah. Adapun berdasarkan hasil olah data diketahui alternatif yang menjadi prioritas dalam upaya peningkatan pengelolaan persampahan/kebersihan di Kecamatan Ngaliyan Kota Semarang adalah sebagai berikut

Tabel 5. Kriteria Peningkatan Pelayanan Penanganan Sampah

\begin{tabular}{clcc}
\hline NO & $\begin{array}{c}\text { Kriteria Aspek Peningkatan Pelayanan } \\
\text { Penanganan Sampah }\end{array}$ & Nilai Bobot & Keterangan \\
\hline 1 & $\begin{array}{l}\text { Penerapan dan peningkatan sistem } \\
\text { pengelolaan persampahan/kebersihan }\end{array}$ & 0.476 & $\begin{array}{c}\text { Inconsistency } \\
\text { Ratio }=0,08\end{array}$ \\
2 & $\begin{array}{l}\text { Penerapan sarana dan prasarana } \\
\text { pengangkutan sampah ke TPA dan } \\
\text { penentuan lokasi TPA yang aman }\end{array}$ & 0.225 & \\
3 & Penerapan sistem pengumpulan sampah & 0.299 & \\
\hline
\end{tabular}

Sumber : Data primer diolah, 2016

Berdasarkan hasil analisis AHP maka diketahui penerapan dan peningkatan sistem pengelolaan persampahan/kebersihan secara langsung merupakan alternatif yang paling menjadi prioritas dalam peningkatan pengelolaan persampahan/kebersihan dari aspek peningkatan pelayanan penanganan sampah dengan persentase prioritas sebesar $47,6 \%$. Selanjutnya yang menjadi prioritas kedua guna meningkatan pengelolaan persampahan/ kebersihan dari aspek peningkatan pelayanan penanganan sampah dalah penerapan sistem pengumpulan sampah dengan persentase perioritas $29,9 \%$.

Terakhir yang menjadi prioritas adalah penerapan sarana dan prasarana pengangkutan sampah ke TPA penentuan lokasi TPA yang aman dengan persentase prioritas sebesar $22,5 \%$. Dari hasil ini telah didapat urutan alternatif strategi yang perlu dilakukan guna peningkatan pengelolaan persampahan/ kebersihan di Kecamatan Ngaliyan Kota Semarang dari aspek peningkatan pelayanan penanganan sampah. Prioritas kedua dalam strategi peningkatan pengelolaan persampahan/ kebersihan adalah aspek pengembangan sistem pembiayaan.
Aspek pengembangan sistem pembiayaan memperoleh persentase prioritas sebesar 26,8\% atau yang terbesar kedua persentase prioritasnya setelah aspek peningkatan pelayanan penanganan sampah. Dalam aspek pengembangan sistem pembiayaan juga terdapat tiga alternatif strategi yaitu penetapan biaya tarif retribusi pengelolaan persampahan/kebersihan sesuai golongan, alternatif selanjutnya yaitu penetapan biaya tarif langsung dan tidak langsung ke TPA, dan alternatif yang terakhir yaitu memberikan sistem pembayaran dengan cara online.

Berdasarkan hasil olah data AHP diketahui prioritas dari aspek pengembangan sistem pembiayaan. Berdasarkan hasil penelitian ini diketahui bahwa penetapan biaya tarif retribusi pengelolaan persampahan/kebersihan sesuai golongan merupakan prioritas yang paling utama dengan persentase sebesar $61,2 \%$. Prioritas kedua yaitu penetapan biaya tarif langsung dan tidak langsung ke TPA dengan persentae sebesar $27,3 \%$, dan prioritas yang terakhir yaitu memberikan sistem pembayaran dengan cara online dengan persentase sebesar $11,4 \%$. 
Tabel 6. Kriteria Pengembangan Sistem Pembiayaan

\begin{tabular}{llll}
\hline NO & $\begin{array}{l}\text { Kriteria Aspek Pengembangan Sistem } \\
\text { Pembiayaan }\end{array}$ & Nilai Bobot & Keterangan \\
\hline 1 & $\begin{array}{l}\text { Penetapan biaya tarif retribusi } \\
\text { pengelolaan persampahan/ kebersihan } \\
\text { sesuai golongan }\end{array}$ & 0,612 & $\begin{array}{l}\text { Inconsistency } \\
\text { Ratio }=0,08\end{array}$ \\
2 & $\begin{array}{l}\text { Penetapan biaya tariff langsung dan tidak } \\
\text { langsung ke TPA }\end{array}$ & 0,273 & \\
3 & $\begin{array}{l}\text { Memberikan siste,m pembayaran dengan } \\
\text { cara online }\end{array}$ & 0,114 & \\
\hline
\end{tabular}

Sumber : Data Primer diolah, 2016

Dalam aspek partisipasi masyarakat ini terdapat tiga alternatif guna peningkatan pengelolaan persmapahan/ kebersihan di Kecamatan Ngaliyan Kota Semarang antara lain partisipasi masyarakat, memeberikan kesadaran masyarakat dalam mengelola sampah gun meningkatkan pengelolaan persmapahan/ kebersihan kemudian pelaksanaan ionformasi dan sosialisasi pengelolaan sampah yang sistematis. Adapun urutan alternatif yang menjadi prioritas dari aspek partisipasi masyarakat berdasarkan hasil olah data

Tabel 7. Kriteria Aspek Partisipasi Masyarakat

\begin{tabular}{clll}
\hline NO & Kriteria Aspek Peran Masyarakat & Nilai Bobot & Keterangan \\
\hline $1 \quad$ & $\begin{array}{l}\text { Partisipasi masyarakat dalam } \\
\text { meningkatkan pengelolaan } \\
\text { persampahan/kebersihan }\end{array}$ & 0,590 & $\begin{array}{l}\text { Inconsistency } \\
\text { Ratio }=0,02\end{array}$ \\
Memberikan kesadaran masyarakat & & \\
$2 \quad$ & $\begin{array}{l}\text { dalam mengelola sampah guna } \\
\text { meningkatkan pengelolaan } \\
\text { persampahan/kebersihan }\end{array}$ & 0,225 & \\
Pelaksanaan informasi dan sosialisasi \\
pengelolaan sampah yang sistematis
\end{tabular}

Sumber : Data Primer diolah, 2016

Dari hasil penelitian ini diketahui bahwa alternatif yang menjadi prioritas utama dalam peningkatan pengelolaan persampahan/kebersihan dari aspek partisipasi masyarakat adalah partisipasi masyarakat dalam dengan persentase sebesar 59\% selanjutnya prioritas kedua yaitu memeberikan kesadaran masyarakat dalam mengelola sampah guna meningkatkan pengelolaan persampahan/kebersihan dengan persentase sebesar 22,5\%. Dan yang menjadi prioritas terakhir dalam upaya peningkatan pengelolaan persampahan/kebersihan adalah pelaksanaan informasi dan sosialisasi pengelolaan sampah yang sistematis dengan persentase sebesar $18,4 \%$.

\section{SIMPULAN}

Berdasarkan hasil penelitian dapat disuimpulkan dengan mempergunakan bantuan alat analisis melalui AHP strategi dari yang paling prioritas terpilihnya alternatif aspek : Aspek peningkatan pelayanan penanganan sampah $(0,504)$ sebagai prioritas utama mencerminkan bahwa peningkatan pengelolaan persampahan/kebersihan di Kecamatan Ngaliyan Kota Semarang sangat erat kaitannya dengan masalah peningkatan pelayanan penanganan sampah, alternatif aspek berikutnya adalah aspek pengembangan sistem pembiayaan $(0,268)$ sebagai prioritas yang kedua dalam strategi peningkatan pengelolaan 
persampahan/kebersihan di Kecamatan Ngaliyan Kota Semarang, selanjutnya yang terakhir alternatif aspek partisipasi masyarakat $(0,228)$. Sebagai prioritas terkahir dalam strategi peningkatan pengelolaan persampahan/kebersihan. Peran masyarakat menjadi prioritas terkahir, ini disebabkan karena pelayanan penanganan sampah yang masih belum merata sehingga peran masyarakat masih kurang dalam meningkatkan pengelolaan persampahan/kebersihan.

Berdasarkan hasil penelitian, diajukan beberapa saran agar peningkatan pengelolaan persampahan/kebersihan di Kecamatan Ngaliyan Kota Semarang dapat lebih maksimal, antara lain untuk lebih memfokuskan: Pelayanan penanganan sampah. Pelyanan dimaksimalkan ke seluruh permukiman di Kota Semarang agar masyarakat lebih mengetahui dengan adanya pengelolaan persampahan/kebersihan, sistem pembayaran di mudahkan karena dengan sistem pemabayaran yang mudah membuat masyarakat akan dengan cepat dan tidak kesulitan dalam melakukan pembayaran pengelolaan persampahan/ kebersihan dan tidak harus membayar ke pihak swasta dalam mengelola sampah, informasi dan sosialisasi tentang pengelolaan sampah sebaiknya dilakukan secara teratur agar masyarakat lebih mengetahui jika adanya pengelolaan persampahan/kebersihan yang diberikan oleh Dinas Kebersihan dan Pertamanan Kota Semarang.

\section{DAFTAR PUSTAKA}

Fitriana, Baiduri Ismayanti. 2013. Implementasi Retribusi Persampahan /Kebersihan di Kabupaten Sleman. Skripsi. Studi Ilmu Administrasi Fiskal. Fakultas Administrasi Publik. Universitas Indonesia.

Hardiyansyah, 2011. Kualitas Pelayanan Publik Konsep, Dimensi, Indikator dan Implementasinya. Cetakan-1. Yogyakarta. Penerbit: Gava Media.

Hariyanto dan Ariyani. 2011. Pengelolaan sampah di Kota Semarang untuj menuju Kota bersih. Junal Ilmu Sosial, Vol 38 No. 1 (2011): Forum Ilmu Sosial.

Jumna, Basudewo Krisna. 2015. Strategi Pengembangan Usaha Tani dalam Upaya Peningkatan Produksi
Padi Organik di Kecamatan Sambirejo Kabupaten Sragen. Economics Development Analisys Journal, Vol 4 No. 3 (2015).

Slamet, J.S. 1996. Kesehatan Lingkungan . Gajah Mada University Press. Yogyakarta.

Sutarto. 2004. Implementasi Kebijakan Persampahan di Kota Semarang. Tesis. Magister Ilmu Administrasi Publik. Universitas Diponegoro.

Yani, Ahmad. 2002. Hubungan Keuangan antara Pemerintah Pusat dan Daerah di Indonesia. Jakarta: PT. Raja Grafindo Persanda.

Saputro, Kismartini dan Syarifudin. 2015. Pengelolaan sampah berbasis masyarakat melalui bank sampah. Jurnal Ilmu Sosial dan Politik, Vol 4 No. 1 (2015): IJC.

Suseno, Deky Aji dan Sunarto. 2012. Strategi kebijakan pengelolaan polder tawang sebagai pengendali banjir dengan pendekatan Analyisis Hierarchy Process (AHP). Jurnal Ekonomi dan Kebijakan, Vol 5 No.1 (2012). March 2012 